\title{
Handling Evaluation of Tractor-semitrailer with Split Fifth Wheel Coupling Undergoing an ISO Double Lane Change Manoeuvre
}

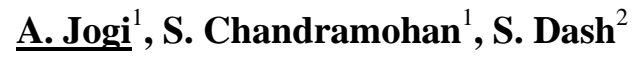 \\ ${ }^{1}$ Department of Mechanical Engineering \\ ${ }^{2}$ Department of Mechanical Engineering \\ Indian Institute of Technology Madras \\ Chennai, India -600036 \\ National Institute of Technology Tiruchirappalli \\ Trichy, India -620015 \\ ajithjogi@gmail.com, sujatha@iitm.ac.in \\ sabyadash21@gmail.com
}

\begin{abstract}
Tractor-semitrailers face the issue of off-tracking which restricts their movement through congested areas. One of the innovative and passive methods to reduce offtracking in tractor-semitrailers is to implement a Split fifth wheel coupling (SFWC). Studies show that off-tracking is reduced by up to $21 \%$ for a circular turning manoeuvre. The handling performance of the tractor-semitrailer with SFWC is not evaluated yet and hence needs to be ad-dressed. In the present work, in order to assess the handling performance of the vehicle with SFWC, simulations are carried out for ISO double lane change manoeuvre at various speeds. The results are compared with those of the Conventional fifth wheel coupling (CFWC) model to understand the relative performance of the tractor-semitrailer with SFWC. The results show that the performance of tractor-semitrailers with SFWC is on par with that of vehicles with CFWC at lower speeds; in fact, for speeds below $40 \mathrm{kmph}$, the lateral acceleration experienced by the semitrailer of SFWC vehicle is less compared to that of CFWC vehicle. However, it becomes a little unstable at higher speeds. With the development of stability control systems like Electronic stability control (ESC), optimized for tractor-semitrailers with SFWC, their performance would improve.
\end{abstract}

Keywords: Split fifth wheel coupling, Off-tracking, Hitch, Tractor-Semitrailer, DLC, Handling

\section{INTRODUCTION}

Tractor-semitrailers are articulated freight carrying vehicles, where a portion of the trailer's load is supported by the tractor. Usually, these are lengthy vehicles making them difficult to manoeuvre in congested roads, since the space required to take the turn increases with wheelbase. Off-tracking is a metric to measure this turning space, which is defined as the radial distance between the trajectory of the front and rearmost axles of a vehicle during the turning manoeuvre. Many researchers, including Jindra [1], Pretty [2] and Choi et al. [3] have worked on the modelling of off-tracking. Steering the semitrailer axle is one of the effective methods for reduction of off-tracking; however, it includes a complex system to control the steering, which makes it expensive. Jogi and Chandramohan [4] have developed a new hitch mechanism, termed Split fifth wheel coupling (SFWC) which reduces the maximum off-tracking by a significant margin. SFWC is a passive mechanism without the inclusion of complex systems.

It is necessary to evaluate the handling performance of the tractor-semitrailer with SFWC to ensure its safe operation. Double lane change (DLC) manoeuvre is one of the handling evaluation methods, wherein the vehicle swiftly changes its lane and comes back to its original lane to avoid an obstacle. There are various kinds of DLC specifications which have been compared with each other by Peng and Yang [5]. ISO DLC is one of the standards for such tests. ADAMS /Car tool is capable of performing the simulations of closed-loop ISO DLC test and provides good results [6]. 


\subsection{SFWC}

The Conventional fifth wheel coupling (CFWC) consists of a turntable fixed to the chassis of the tractor. It receives the kingpin of the semitrailer, forming a joint which serves not only as an articulation point, but also as the point of vertical load transfer from the semitrailer to the tractor. Figure 1 (a) shows the conceptual model of the tractor-semitrailer with CFWC. On the other hand, SFWC being a novel off-racking reduction mechanism, the articulation point and the point of vertical load transfer have been separated by a certain distance. It consists of two subunits: cylindrical joint and roller mechanism, as shown in Figure 1 (b). The former takes care of articulation, whereas the latter allows the vertical load transfer from the semitrailer to the tractor even when the vehicle is articulating. Studies have shown that the SFWC, when equipped on the conventional tractor-semitrailer, reduces maximum off-racking by up to $21 \%$ for a circular manoeuvre [4]. When analysed for $90^{\circ}$ and $180^{\circ}$ turning manoeuvre, it was found to reduce the maximum off-racking by up to $13.9 \%$ and $14.7 \%$ respectively [7].

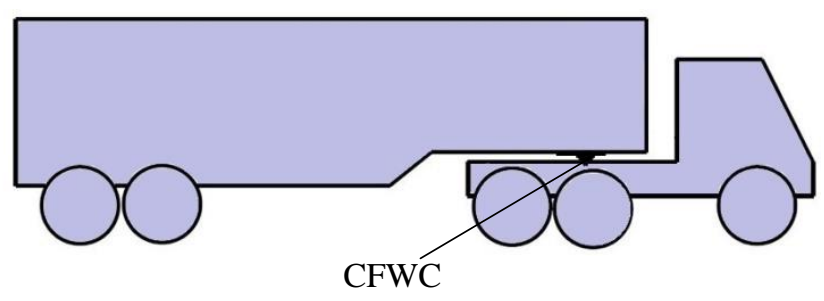

(a)

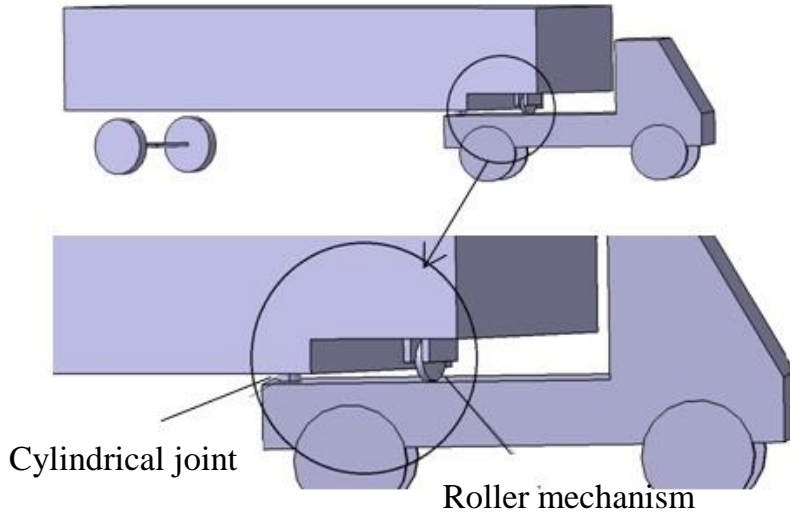

(b)

Figure 1. Conceptual model of the tractor-semitrailer with (a) CFWC (b) SFWC (Courtesy: Jogi and Chandramohan [7]).

\section{METHODOLOGY}

In the present work, a multi-body virtual prototype is built using the ADAMS Car tool. Initially, the CFWC model is built as per the specifications of AASHTO Standard Design Interstate Tractor-Trailer WB-62, specifications of which are mentioned in Appendix 1. Using the template builder option, CFWC model is modified into SFWC, by adding a roller mechanism and curved track. The kingpin offset chosen for the SFWC model is $812.8 \mathrm{~mm}$. To evaluate the handling performance of the vehicle with SFWC, it is simulated for closed-loop ISO double lane change (DLC) manoeuvre, the specifications of which are mentioned in Figure 2. Five speeds are chosen for the study: $20 \mathrm{kmph}$ to $60 \mathrm{kmph}$ with an interval of $10 \mathrm{kmph}$.

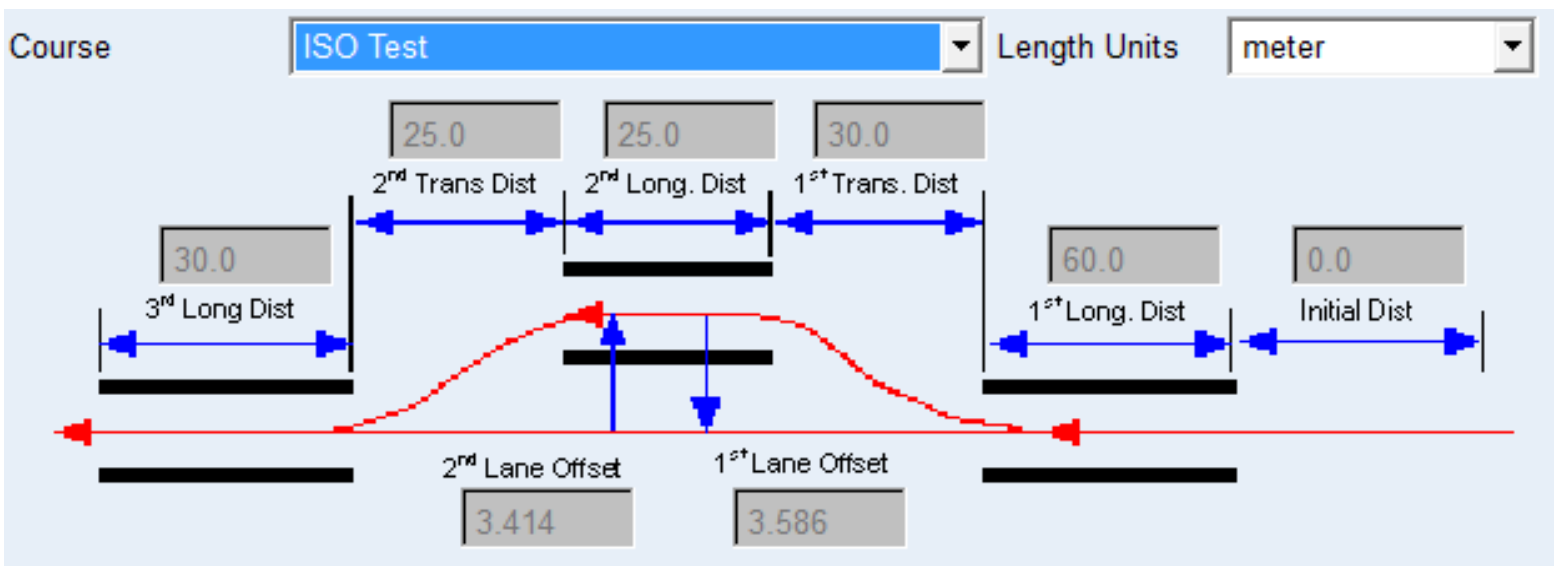

Figure 2. Specifications of ISO DLC course for heavy vehicles (Courtesy: MSC Software Corporation [8]) 
As shown in Figure 2, the actual length of the ISO DLC course is $170 \mathrm{~m}$; however, to study the behaviour of the vehicle after finishing the course, the vehicle is run for an additional distance of about $130 \mathrm{~m}$. The turn direction is chosen to be right for all simulation runs. The default value for the caster, camber and toe angles are chosen as $0^{\circ}$. Gear position is selected as suggested by the tool for the engine speed to be in the range between stall speed and max revolutions per minute limit. The default 2D flat road and default controller are used for all simulation runs. The simulation data are used to plot the trajectory, yaw rate response, lateral acceleration response and articulation angle response of both the vehicle models. To understand the relative performance of the tractor-semitrailer with SFWC, the results of both models are compared with each other and useful conclusions are drawn.

\section{RESULTS AND DISCUSSION}

The comparison of trajectories of the two vehicles at different velocities with respect to the target path is carried out. This gives insight into the ability of the vehicle to follow the ISO DLC path at various speeds. Figure 3 shows the trajectory of the tractor and semitrailer units of both SFWC and CFWC models at speeds varying from $20 \mathrm{kmph}$ to $60 \mathrm{kmph}$ with a step size of 10 $\mathrm{kmph}$. One can observe that both the models trace the ISO double lane change path pretty well. The path traced by the units of tractor-semitrailer with SFWC matches that of the respective units of the CFWC model for speeds below $40 \mathrm{kmph}$. At $50 \mathrm{kmph}$ speed, both vehicles show some instability after exiting the last turn of the DLC course. At $60 \mathrm{kmph}$ the SFWC model tends to oscillate more than the CFWC model; however, both models complete the test without the lift-off of any of their wheels. Since the behaviour of both vehicles is similar at speeds below $40 \mathrm{kmph}$, the trajectory of the tractor unit of SFWC model exactly matches that of CFWC. However, at $40 \mathrm{kmph}$ speed one can observe that the semitrailer unit of SFWC traces comparatively an inner path. Since its path is slightly closer to that of its tractor, one can understand that the off-tracking posed by SFWC model is less.
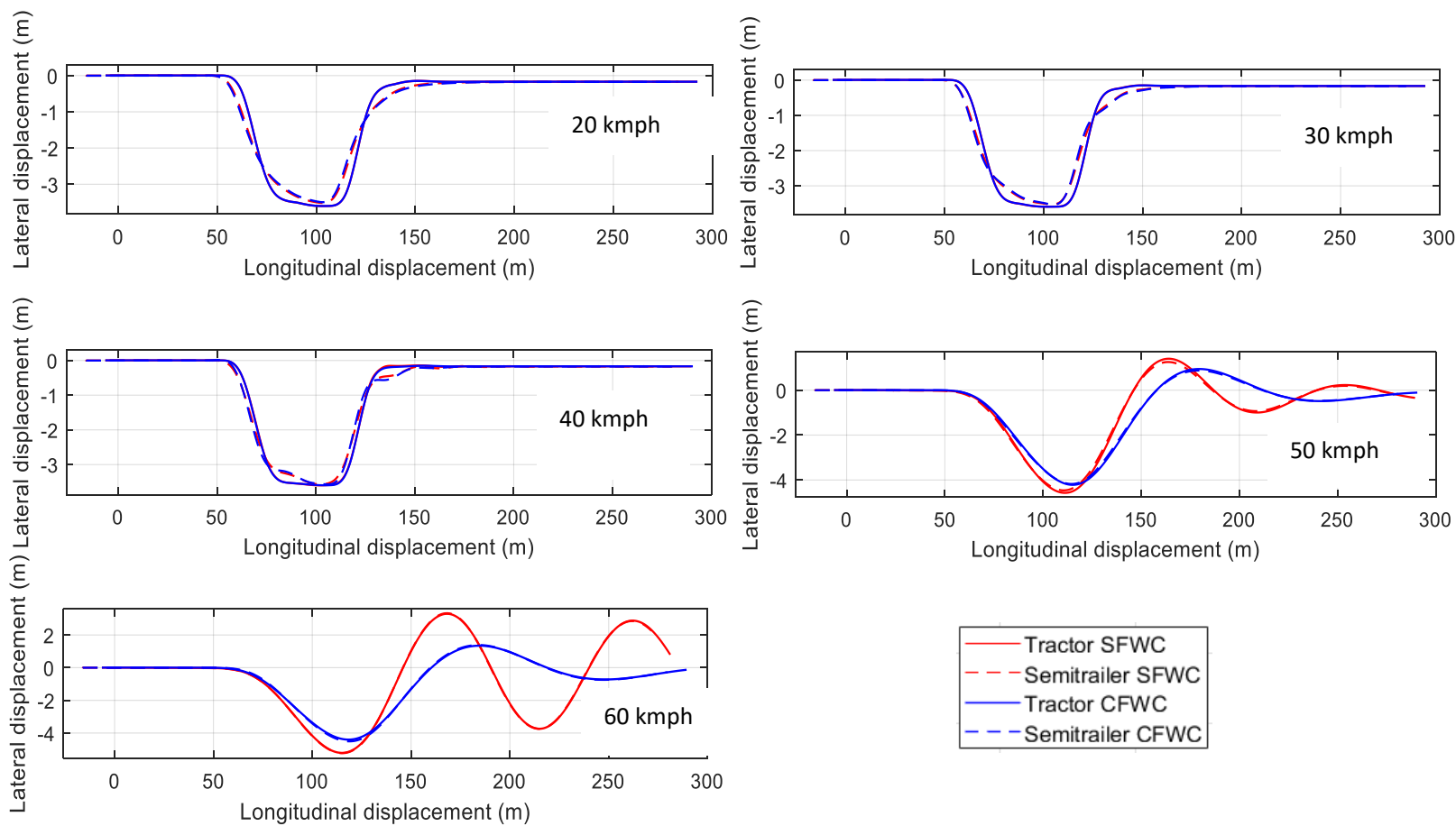

Figure 3. Trajectory of the tractor-semitrailer with SFWC and CFWC at various speeds

Figure 4 shows the yaw rate response of the vehicles at different speeds. The yaw rate response of both SFWC and CFWC models match each other at $20 \mathrm{kmph}$, however, at $30 \mathrm{kmph}$ there is a noticeable difference during the last turn of the DLC course. This difference is even more pronounced at $40 \mathrm{kmph}$, the yaw rate of the SFWC model being higher during the turns. The trend of the yaw rate response is similar for speeds 20, 30 and $40 \mathrm{kmph}$. At 50 and $60 \mathrm{kmph}$ speeds, the trend is quite different from the rest because of the instabilities arising due to the high-speed cornering. 

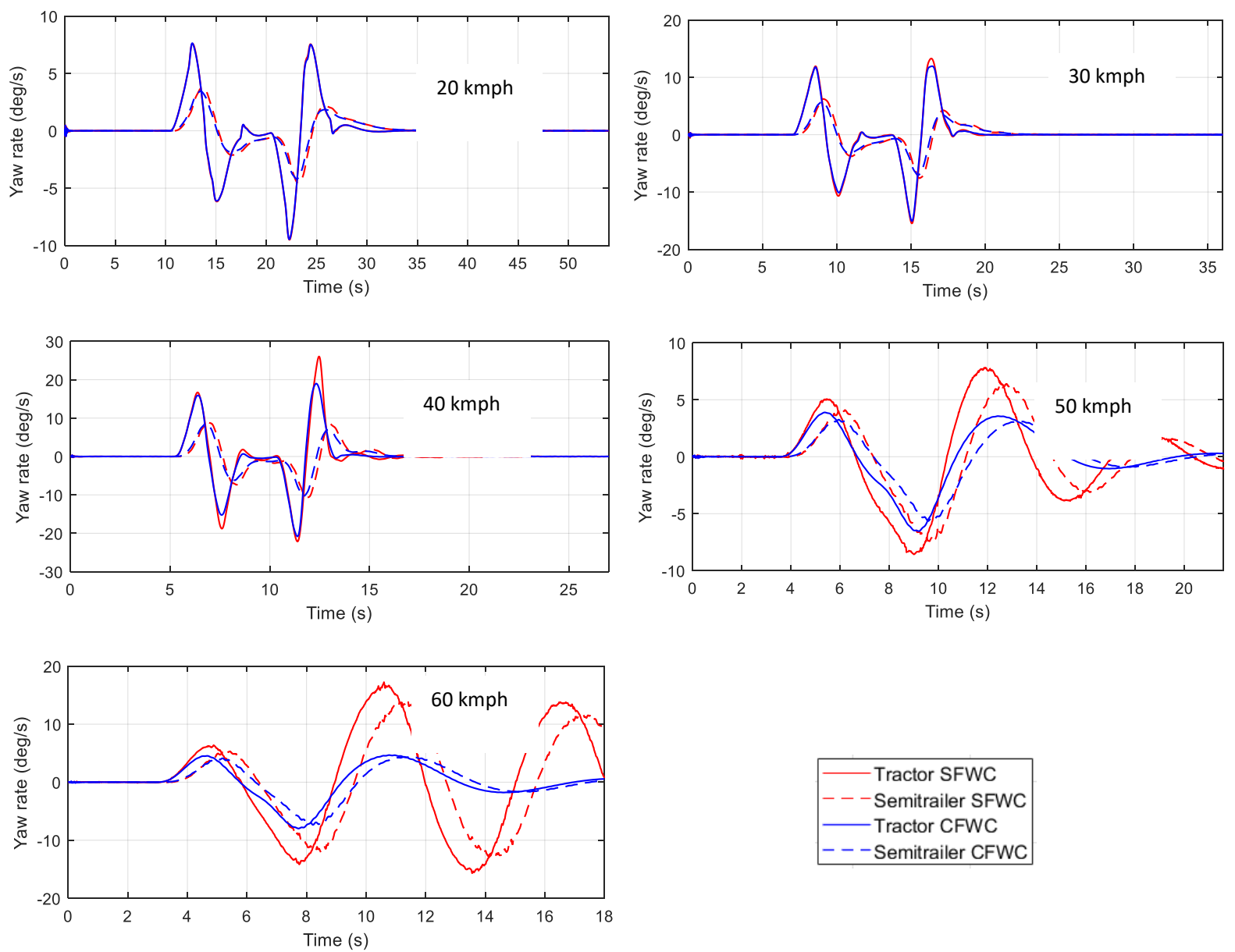

Figure 4. Yaw rate response of the tractor-semitrailer with SFWC and CFWC at various speeds

The study of the lateral acceleration experienced by the vehicle plays an important role. Figure 5 shows the lateral acceleration response of the vehicle tractor and semitrailer at different speeds. There is a noise in the lateral acceleration data during the beginning of the simulation run and can be ignored. Again, the trend followed by the lateral acceleration response at speeds 50 and $60 \mathrm{kmph}$ is different from that of 20,30 and $40 \mathrm{kmph}$ for both the vehicle models. One can observe that the peak lateral accelerations experienced by the vehicle units occur during the turns. Also, the semitrailer units experience less lateral acceleration when compared to their respective tractors, due to the fact that, their path is comparatively a smoothened curve, which is evident from the trajectory plots. Interestingly, the lateral acceleration experienced by the semitrailer of SFWC vehicle is less when compared to that of CFWC vehicle for speeds below $40 \mathrm{kmph}$. Due to high speeds, the vehicles are not able to take sharp turns, which is evident from the yaw rate response for 50 and $60 \mathrm{kmph}$. Hence, corresponding lateral acceleration values also decrease when compared to those of $40 \mathrm{kmph}$. The actual curves for lateral acceleration for both units of SFWC at speeds 50 and $60 \mathrm{kmph}$ contain a large amount of noise and hence are smoothened (smoothing parameter $\mathrm{p}=0.999$ ) for better representation. The actual plots and curve-fitting data can be found in Appendix 2.
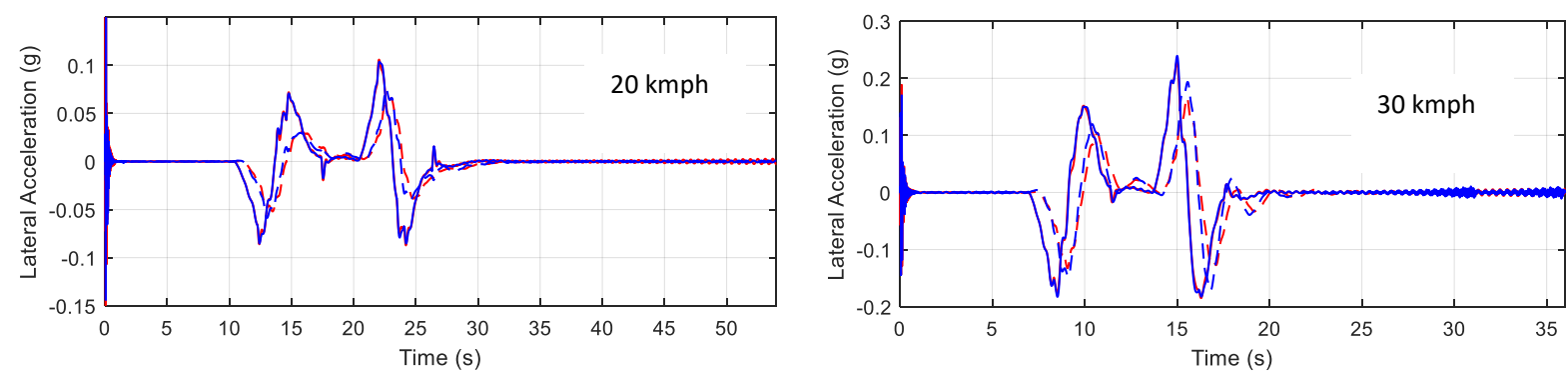

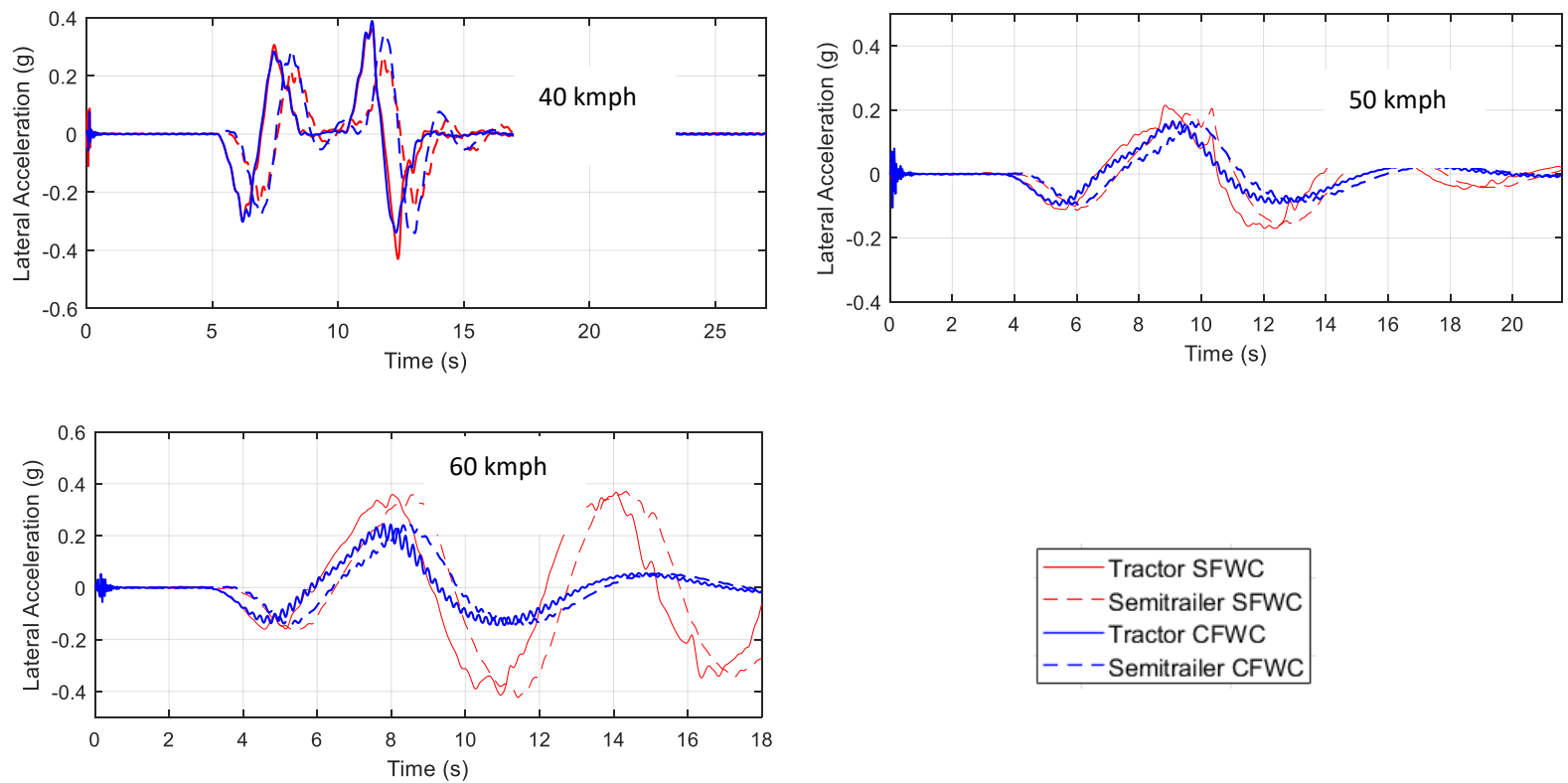

Figure 5. Lateral acceleration response of the tractor-semitrailer with SFWC and CFWC at various speeds

Figure 6 shows the articulation angles of the tractor and semitrailer units of both SFWC and CFWC models at speeds varying from $20 \mathrm{kmph}$ to $60 \mathrm{kmph}$ at intervals of $10 \mathrm{kmph}$. Again, the trend of the articulation angle curve for speeds between 20 and $40 \mathrm{kmph}$ are similar to each other and different from the rest of the speeds. The articulation angle of SFWC vehicle is comparatively higher at all the speeds, owing to the fact that the effective wheelbase of the semitrailer of the SFWC vehicle is smaller, the overall length being the same.
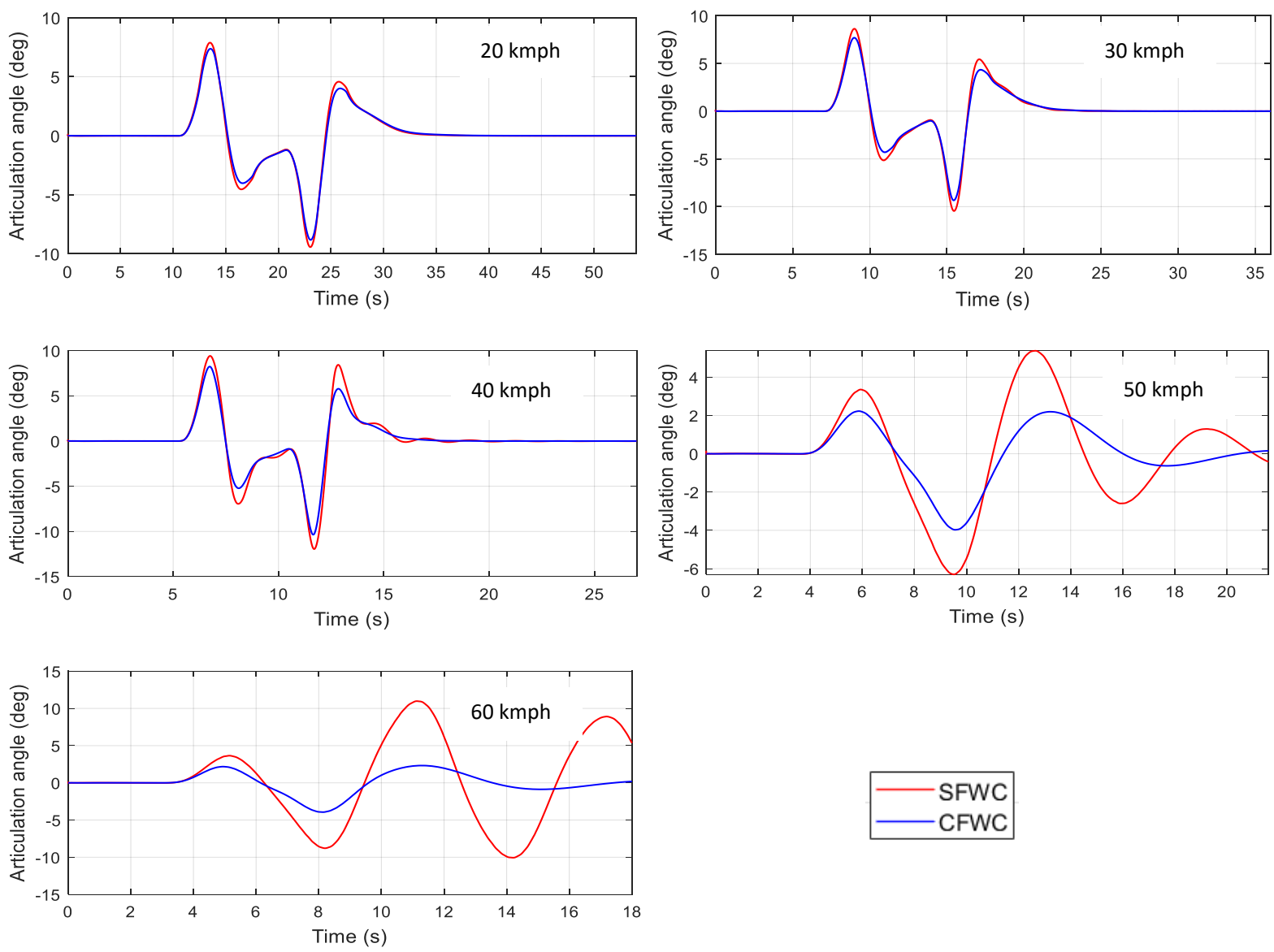

Figure 6. Articulation angle curves of the tractor-semitrailer with SFWC and CFWC at various speeds 


\section{SUMMARY AND CONCLUSION}

To study the handling characteristics of the tractor-semitrailer with SFWC in comparison with the conventional vehicle, the DLC test is carried out, which is an obstacle avoidance manoeuvre. The virtual prototypes of both the vehicle types have been subjected to ISO DLC using the ADAMS/ Car tool at different speeds ranging from $20 \mathrm{kmph}$ to $60 \mathrm{kmph}$ with a step size of 10 $\mathrm{kmph}$. The SFWC model traces the target path pretty well at lower speeds; however, it is a little unstable at higher speeds when compared to the CFWC model. The behaviour of both vehicles changes significantly between from 40 to $50 \mathrm{kmph}$. The lateral acceleration response explains that the DLC is a very dynamic manoeuvre and can generate rapid rates of change of lateral acceleration. Interestingly, for speeds below $40 \mathrm{kmph}$, the lateral acceleration experienced by the semitrailer of SFWC vehicle is less compared to that of CFWC vehicle. One should note that the DLC manoeuvre is highly dependent on the driver's steering input. The default driver model present in ADAMS/ Car tool is optimized for the tractor-semitrailer with CFWC. Hence, the actual steering input to be given to SFWC vehicles may vary. In the present study, the performance of the tractor-semitrailer with SFWC is on par with that of CFWC at speeds below 50 $\mathrm{kmph}$. The vehicle's inability to trace the ISO DLC path is more pronounced at higher speeds. With the development of stability control systems like ESC, optimized for tractor-semitrailers with SFWC, their performance would improve.

\section{REFERENCES}

[1] F. Jindra, Off-tracking of Tractor-trailer Combinations. J. Automob. Eng. 96-101, 1963.

[2] R.L. Pretty, On the off-tracking of semi-trailers. ARRB Proceedings, vol. 2, Part 1, 1964.

[3] J. Choi, J. Baek, S. Lee, W. Kang, Offtracking model on horizontal curve sections. Eastern Asia Society for Transportation Studies, vol. 3, No. 1, 2001.

[4] A. Jogi, S. Chandramohan, Kinematic analysis of tractor-semitrailer with split fifth wheel coupling during low speed turning maneuvers, SAE Int. J. Commer. Veh. 10(2): 2017, doi:10.4271/2017-011554, 2017.

[5] Y. Peng, X. Yang, Comparison of various double lane change manoeuvre specifications, Vehicle System Dynamics, 50:7, 1157-1171, DOI: 10.1080/00423114.2012.659741, 2012.

[6] N. Khettou, D. Trifkovic, S. Muzdeka, Using modelling and simulation to predict dynamics of converted ground vehicle, Defence Science Journal, Vol. 66, No. 5, pp. 509-516, DOI : 10.14429/dsj.66.9783, 2016.

[7] A. Jogi, S. Chandramohan, Zero-speed off-tracking analysis of tractor-semitrailer with split fifth wheel coupling for $90^{\circ}$ and $180^{\circ}$ turning manoeuvres, Biswal B., Sarkar B., Mahanta P. (eds) Advances in Mechanical Engineering, Lecture Notes in Mechanical Engineering. Springer, Singapore, 2020 .

[8] MSC ADAMS Car 2019.2 help document (MSC.Software\Adams 2019 \help ladams_carldialogboxesłdbox_ana_ful_ilc_sub.html) 


\section{APPENDIX 1}

Specifications of reference tractor-semitrailer: Interstate Tractor-Trailer WB-62

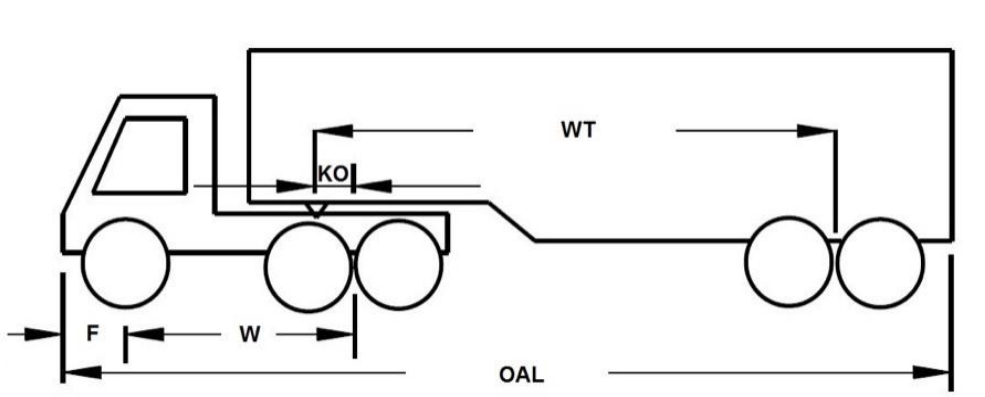

Tractor wheelbase (W)

$6.10 \mathrm{~m}$

Front overhang $(\mathrm{F})$

$0.91 \mathrm{~m}$

Semitrailer wheelbase (WT)

$12.80 \mathrm{~m}$

Kingpin offset (KO)

$0.30 \mathrm{~m}$

Overall length (OAL)

$21.03 \mathrm{~m}$

Figure A1. Specifications of reference tractor-semitrailer Interstate Tractor-Trailer WB-62

\section{APPENDIX 2}

The lateral acceleration response (with noise) and curve-fitting data
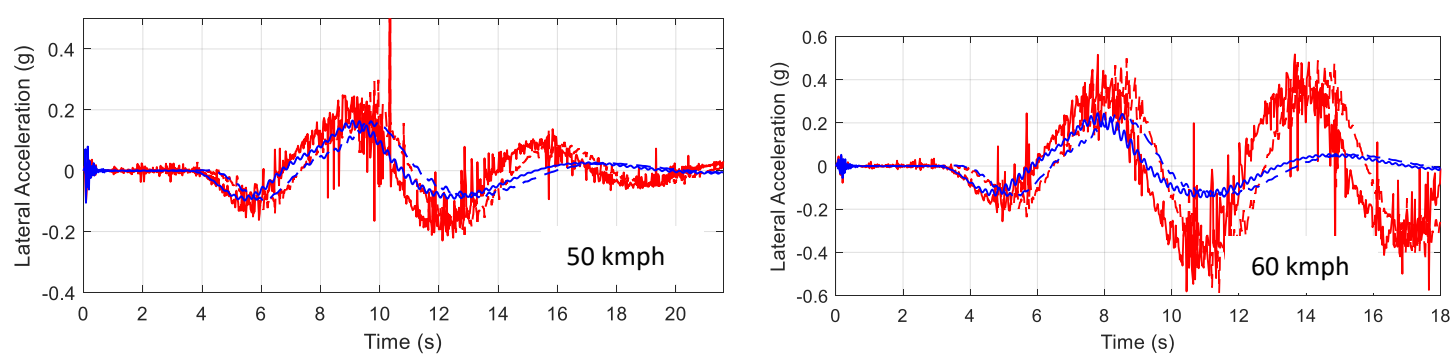

Figure A2. Lateral acceleration response of the tractor-semitrailer with SFWC and CFWC at 50 and $60 \mathrm{kmph}$ speed without smoothing of the curves

Curve fitting data for SFWC lateral acceleration response:

- Smoothing spline: $\quad f(x)=$ piecewise polynomial computed from $p$

- Smoothing parameter: $\mathrm{p}=0.999$

Table A2. Goodness parameters of the fit

\begin{tabular}{|c|c|c|}
\hline & SFWC Tractor & SFWC Trailer \\
\hline SSE & 1.907 & 0.871 \\
\hline R-square & 0.7993 & 0.8946 \\
\hline Adjusted R-square & 0.7769 & 0.8828 \\
\hline RMSE & 0.04296 & 0.02903 \\
\hline
\end{tabular}

